\title{
Oxygenation failure after cardiac surgery: early re-intubation versus treatment by nasal continuous positive airway pressure (NCPAP) or non-invasive positive pressure ventilation (NPPV)
}

\section{Ipossia dopo chirurgia cardiaca: re-intubazione precoce verso trattamento a pressione positiva nasale continua (NCPAP) o ventilazione a pressione positiva non invasiva (NPPV)}

\author{
Muhammed Kurt, Udo Boeken, Jens Litmathe, Peter Feindt, Emmeran Gams
}

\begin{abstract}
Oxygenation failure after cardiac surgery: early re-intubation versus treatment by nasal continuous positive airway pressure (NCPAP) or non-invasive positive pressure ventilation (NPPV). M. Kurt, U. Boeken, J. Litmathe, P. Feindt, E. Gams.

Background: Due to an increasing incidence of respiratory failure after cardiac surgery we wanted to study whether nasal continuous positive airway pressure (NCPAP) may improve pulmonary oxygen transfer and may avoid reintubation after coronary operations. Additionally, we compared this protocol to non-invasive positive pressure ventilation (NPPV).

Methods: For a period of 2 years we analyzed all patients that were extubated within 12 hours after coronary surgery, and in whom oxygen transfer $\left(\mathrm{PaO}_{2} / \mathrm{FIO}_{2}\right)$ deteriorated without hypercapnia so that all these patients met predefined criteria for reintubation: group $A=$ =immediate reintubation ( $n=88)$, group $B=$ NCPAP-treatment $(n=173)$, group $\mathrm{C}=\mathrm{NPPV}(\mathbf{n}=\mathbf{1 8})$.
\end{abstract}

Results: $25,4 \%$ of group B- and $22,2 \%$ of group C-patients were also intubated after a period of NCPAP or NPPV. All other patients of groups $B$ and $C$ could be weaned from these devices $(B=\mathbf{3 4 . 3} \pm \mathbf{5 . 9}$ hours; $C=\mathbf{2 6 . 4} \pm$ $4.4 \mathrm{~h} ; \mathrm{p}<0.05)$ and were well oxygenated by face mask at ambient pressure (Ratio $\mathrm{PaO}_{2} / \mathrm{FIO}_{2}: \mathrm{B}, 138 \pm 13 ; \mathrm{C}, 140 \pm 13$ ). In group A we found a higher mortality $(\mathbf{7 . 9 5 \% )}$ ) compared to group B $(4.04 \%)$ and group C $(5.55 \%)$. NCPAP-patients suffered more frequently from an impaired sternal wound healing $(A=4.5 \%, B=8.6 \% ; p<0.05)$.

Conclusions: We conclude that reintubation after cardiac operations should be avoided since NCPAP and NPPV are safe and effective to improve arterial oxygenation in most patients with non hypercapnic respiratory failure.

Keywords: cardiac surgery, respiratory failure, reintubation, non-invasive positive pressure ventilation (NPPV), nasal continuous positive airway pressure (NCPAP).

Monaldi Arch Chest Dis 2008; 70: 71-75.

Department of Thoracic and Cardiovascular Surgery, Heinrich-Heine-University Hospital, Duesseldorf, Germany

Corresponding author: Jens Litmathe MD, PhD; Department of Thoracic- and Cardiovascular Surgery; Moorenstrasse 5; D-40225 Duesseldorf, Germany; E-mail address: litmathe@med.uni-duesseldorf.de

\section{Introduction}

Cardiac surgical intervention has become a common method of treating coronary artery disease and valvular dysfunction. More than 95.000 procedures have been performed all over Germany in 2004 and about 1300 adult cardiac surgical procedures are performed annually at the University Hospital of Duesseldorf. Weaning from mechanical ventilation usually proceeds an endotracheal extubation instantaneously. Failure of the patient to tolerate extubation may reflect premature extubation or be a marker of a critically ill patient. A few studies have focused on the incidence of reintubation, the factors associated and on the patients' outcome [1-3]. Avoiding endotracheal reintubation and mechanical ventilation by noninvasive ventilatory support is known to significantly reduce infectious complications, duration of ICU therapy, and mortality, so that its benefits are generally accepted [4].
The current study reflects the experience at our institution over a period of two years and compares the outcomes of patients undergoing endotracheal reintubation with those receiving non-invasive ventilatory support either as nasal continuous positive airway pressure (NCPAP- Evita XL ${ }^{\odot}$, Dräger, D) or as non-invasive positive pressure ventilation (NPPV- BIPAP-Vision ${ }^{\circledR}$, Respironics, US).

\section{Patients and Methods}

All records of patients who underwent a coronary artery bypass grafting operation at our institution over a period of 2 years and were extubated within 12 hours after surgery and in whom pulmonary oxygen transfer $\left(\mathrm{PaO}_{2} / \mathrm{FIO}_{2}\right)$ deteriorated without hypercapnia were reviewed. All these patients met commonly accepted criteria for reintubation. All valve replacement procedures were exclud- 
ed from this study, even in cases of concomitant coronary artery bypass grafting.

Altogether 279 of all patients undergoing an isolated coronary artery bypass grafting operation met after primary extubation the criteria for reintubation. Patients suffering from a lack of consciousness and/or hypercapnia underwent immediate reintubation, all other received non-invasive ventilation support. The entire cohort was divided into three study-groups: Group $\mathrm{A}=$ immediate reintubation $(n=88)$, group $B=$ NCPAP-treatment $(n=173)$ and group $C=\operatorname{NPPV}(n=18)$. All relevant clinical data as well as important hemodynamic measures, such as heart rate (HR), mean arterial pressure (MAP) and central venous pressure (CVP) and furthermore the ratio of $\mathrm{PaO}_{2}$ and $\mathrm{FiO}_{2}$ were listed.

The perioperative characteristics for all three groups are shown in table 1.

\section{Operative details and proceeding at the ICU}

All operations were performed using a median sternotomy, with help of cardiopulmonary bypass (CPB) in mild hypothermia and cardioplegic arrest using either Bretschneider's solution or the Calafiore-technique. In all cases a coronary artery bypass grafting $(\mathrm{CABG})$ was carried out.
After transfer to the intensive unit care (ICU), the patients were weaned from the respirator following a standard regime. They were extubated when vigilance and oxygenation $\left(\mathrm{pO}_{2}>60 \mathrm{mmHg}\right.$ at $\left.\mathrm{FiO}_{2} 0.3\right)$ were satisfactory. In detail standard criteria for extubation were defined as respiratory rate of 10 to 28 breaths/min, tidal volume higher than $5 \mathrm{ml} / \mathrm{kg}$ body weight, vital capacity greater than $10 \mathrm{ml} / \mathrm{kg}$ body weight and the ability to maintain adequate oxygenation with supplemental oxygen below $40 \% \mathrm{FiO}_{2}$.

The follow-up included at maximum the in-hospital-stay.

\section{Statistical analysis}

Descriptive measures are given as mean values with the standard error of the mean (SEM). Comparisons between groups were performed using the $X^{2}$ test or with Student's $t$ - test as appropriate. A p-value $\leq 0.05$ was considered to be statistically significant.

\section{Results}

The clinical status was comparable in all three groups, just the elapsed time since primary extubation was significantly shorter in patients undergoing NCPAP-therapy (group B, table 2).

Table 1. - Perioperative patients ' characteristics in groups A, B and C

\begin{tabular}{lcccc}
\hline & group A $(\mathbf{n = 8 8})$ & group B (n=173) & group C (n=18) & p(A/B) \\
\hline age (years) & $64.1 \pm 12.3$ & $64.5 \pm 11.3$ & $65.1 \pm 12.1$ & $>0.05$ \\
\hline gender (\% male) & 78 & 75 & 76 & $>0.05$ \\
\hline body mass index & $25.4 \pm 3.5$ & $25.0 \pm 3.3$ & $26.2 \pm 3.8$ & $>0.05$ \\
\hline preop. EF (\%) & $62 \pm 8.5$ & $61 \pm 8.2$ & $63 \pm 7.8$ & $>0.05$ \\
\hline emergency op. (\%) & 3.4 & 2.9 & 5.5 & $>0.05$ \\
\hline duration of op. $(\mathbf{m i n})$ & $211 \pm 23$ & $218 \pm 25$ & $209 \pm 21$ & $>0.05$ \\
\hline duration of ischemia $(\mathbf{m i n})$ & $48 \pm 6$ & $47 \pm 7$ & $49 \pm 9$ & $>0.05$ \\
\hline number of grafts $(\mathbf{n})$ & $3.7 \pm 0.5$ & $3.5 \pm 0.4$ & $3.4 \pm 0.4$ & $>0.05$ \\
\hline LIMA-utilization $(\%)$ & 91 & 88 & 89 & $>0.05$ \\
\hline LCOS $(\%)$ & 5.6 & 5.7 & 5.5 & $>0.05$ \\
\hline
\end{tabular}

Table 2. - Clinical status before re-ITN (A), NCPAP (B) and NPPV (C)

\begin{tabular}{|c|c|c|c|c|}
\hline & group A $(n=88)$ & group $B(n=173)$ & group $C(n=18)$ & $\mathbf{p}(\mathbf{A} / \mathbf{B})$ \\
\hline conscious $(\%)$ & 91 & 100 & 100 & $<0.05$ \\
\hline $\mathrm{P}_{\mathrm{a}} \mathrm{CO}_{2}(\mathrm{mmHg})$ & $49.8 \pm 7.5$ & $45.5 \pm 6.4$ & $45.8 \pm 6.2$ & $<0.05$ \\
\hline catecholamines (\%) & 16.8 & 17.1 & 16.5 & $>0.05$ \\
\hline temperature $>38^{\circ} \mathrm{C}(\%)$ & 11.4 & 11.0 & 11.1 & $>0.05$ \\
\hline neurologic problems (\%) & 3.4 & 2.9 & 5.5 & $>0.05$ \\
\hline bleeding problems (\%) & 3.4 & 3.5 & 5.5 & $>0.05$ \\
\hline prim. ventil. time (h) & $6.8 \pm 0.9$ & $6.5 \pm 0.8$ & $7.0 \pm 1.0$ & $>0.05$ \\
\hline time since prim. extub. (h) & $6.6 \pm 1.4$ & $5.1 \pm 0.8$ & $6.4 \pm 1.0$ & $<0.05$ \\
\hline
\end{tabular}


$25,4 \%$ of group B- and $22,2 \%$ of group C-patients were also intubated after a period of CPAP or NPPV. All other patients of groups $\mathrm{B}$ and $\mathrm{C}$ could be weaned from these devices (B: $34.3 \pm 5.9$ hours; $C: 26.4 \pm 4.4$ $\mathrm{h} ; \mathrm{p}<0.05)$ and were well oxygenated by face mask at adequate pressure $\left(\mathrm{PaO}_{2} / \mathrm{FIO}_{2}\right.$ : $\mathrm{B}: 138 \pm 13, \mathrm{C}: 140 \pm 13$ after finishing). The ratio was significantly increased in group A during the first 24 hours of observation, figure 1 ).

In group $\mathrm{A}$ a higher mortality $(7.95 \%)$ compared group B $(4.04 \%)$ and group C $(5.55 \%)$ was observed. Stay on ICU and in-hospital-stay was significantly prolonged in group $\mathrm{A}$. The incidence of pulmonary infections (A: $22.7 \%, \mathrm{~B}: 10.4 \%, \mathrm{C}$ : $11.1 \%, \mathrm{p}<0.05)$ and the need for catecholamines were significantly increased in group A, whereas NCPAP-patients significantly more often suffered from an impaired sternal wound healing (A: $4.5 \%, \mathrm{~B}: 8.6 \%$, $\mathrm{p}<0.05$, figures 2 and 3 ).

Central venous pressure (CVP) and mean arterial blood pressure (MAP) had a different behaviour: CVP was significantly higher in group B compared to group A 4, 8 and 24 hours after start of observation, whereas MAP was significantly higher in group A 8 and 24 hours after onset of observation (figures 4 and 5). Finally, heart rate (HR) was significantly higher in group A 8, 12 and 24 hours after onset of observation (figure 6).

\section{Discussion}

The patient population in cardiac surgery has significantly changed during the last two decades: Since interventional cardiology especially in coronary artery disease has tremendously improved, both cardiac pathology and concomitant clinical status of patients scheduled for $\mathrm{CABG}$ have impressively impaired [5]. Thus, the individual treatment for each patient has the main goal to avoid adverse events in order to optimize the immediate postoperative outcome. Early extubation is a

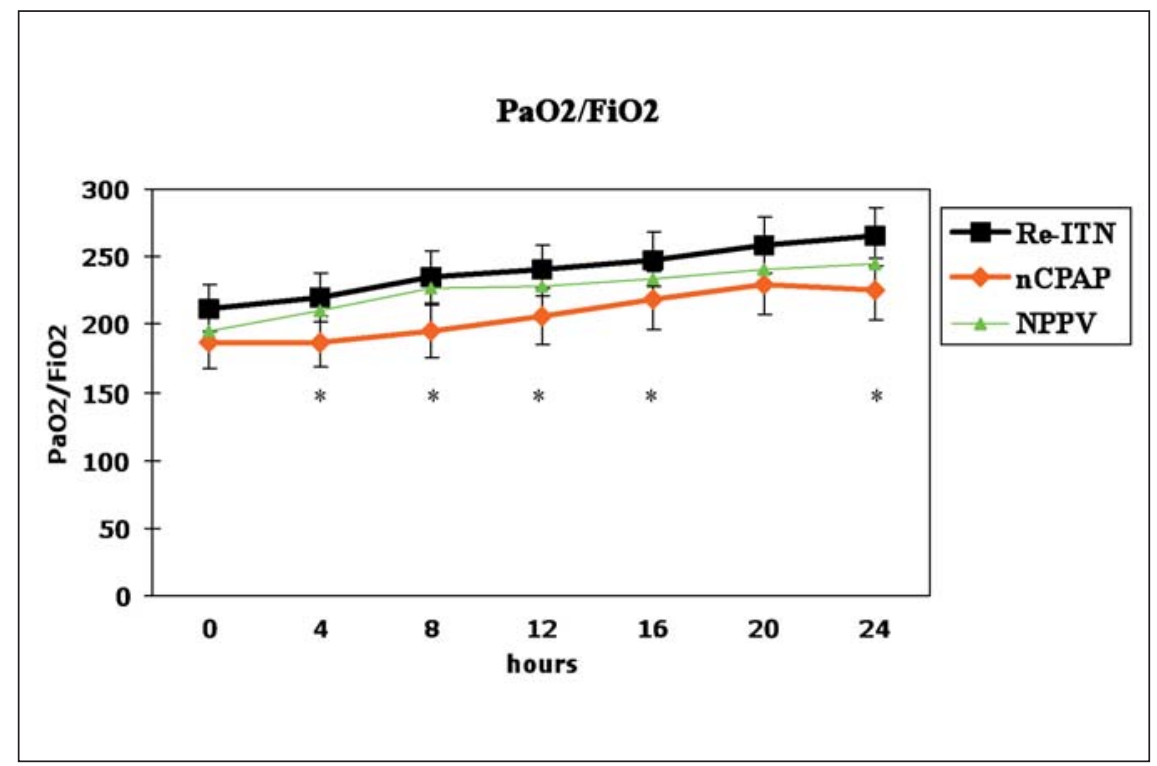

Figure 1. - Ratio $\mathrm{PaO}_{2} / \mathrm{FiO}_{2}$ during the first 24 hours of observation, ${ }^{*}=\mathrm{p}<0.05$ group A vs. B.

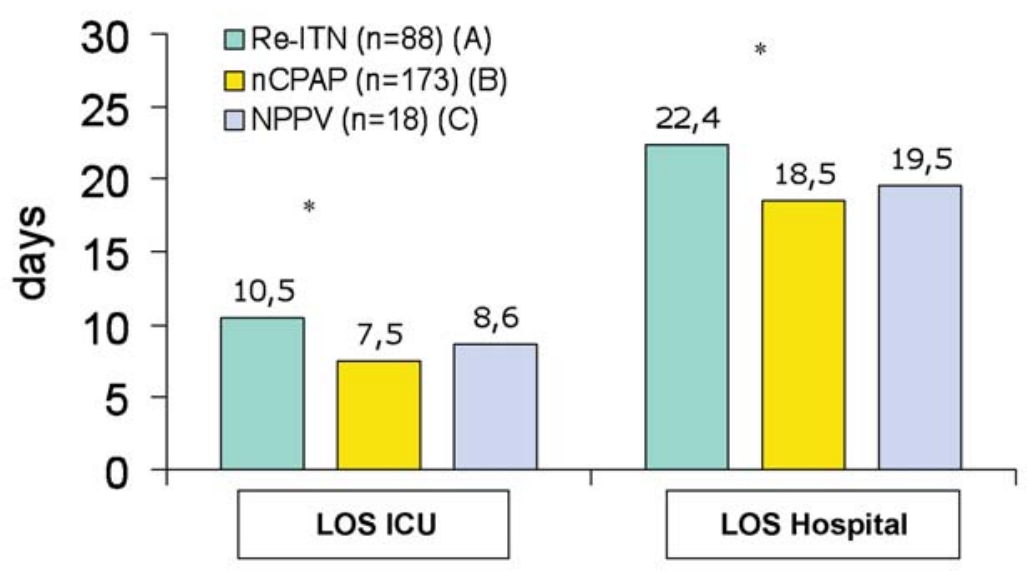

Figure 2. - Length of stay (LOS) at ICU and in hospital in all three groups, ${ }^{*}=\mathrm{p}<0.05$ group A vs. B.

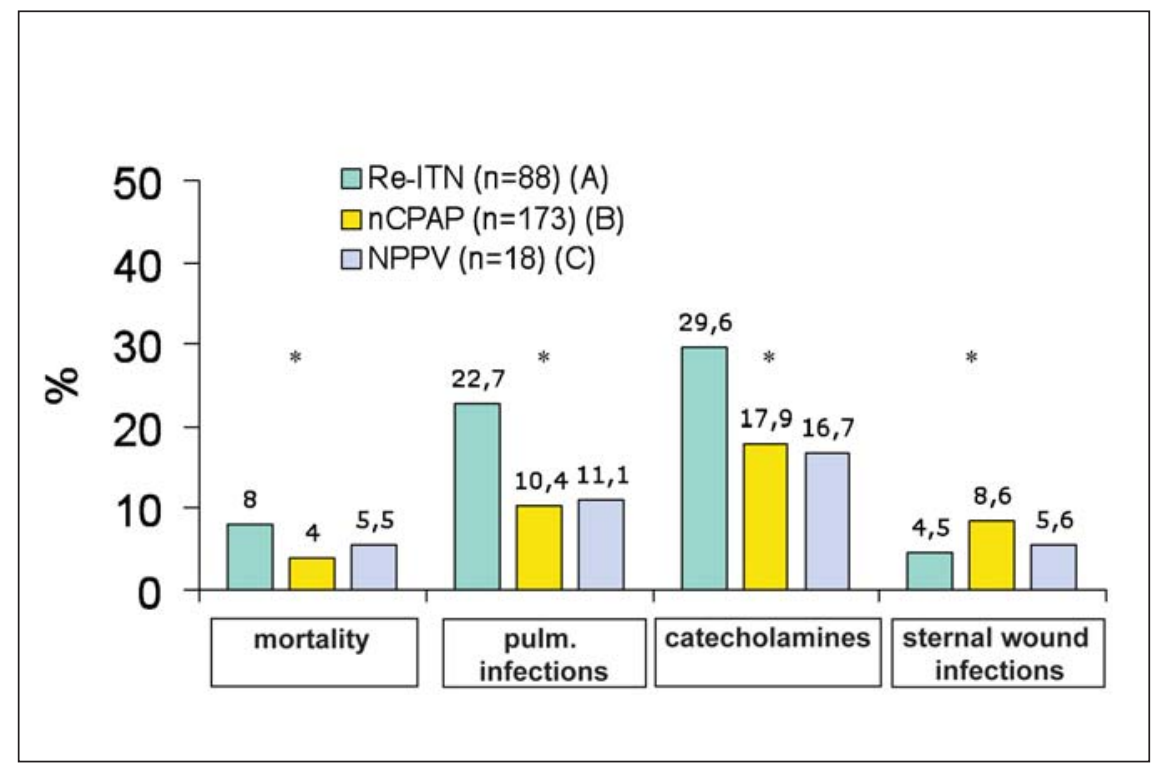

Figure 3. - Mortality and major complications in all three groups, $*=p<0.05$ group A vs. B. 


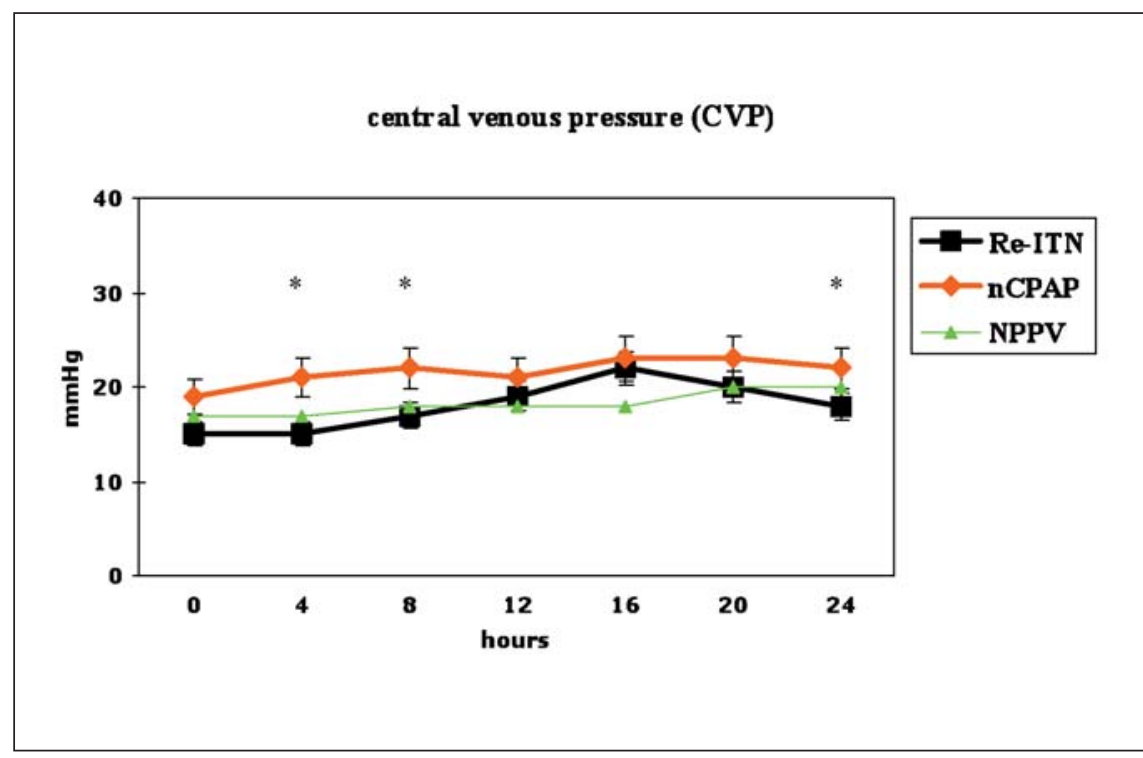

Figure 4. - Central venous pressure (CVP) during the first 24 hours of observation $(*=\mathrm{p}<0.05$ for group A [re-ITN] vs. group B [nCPAP]).

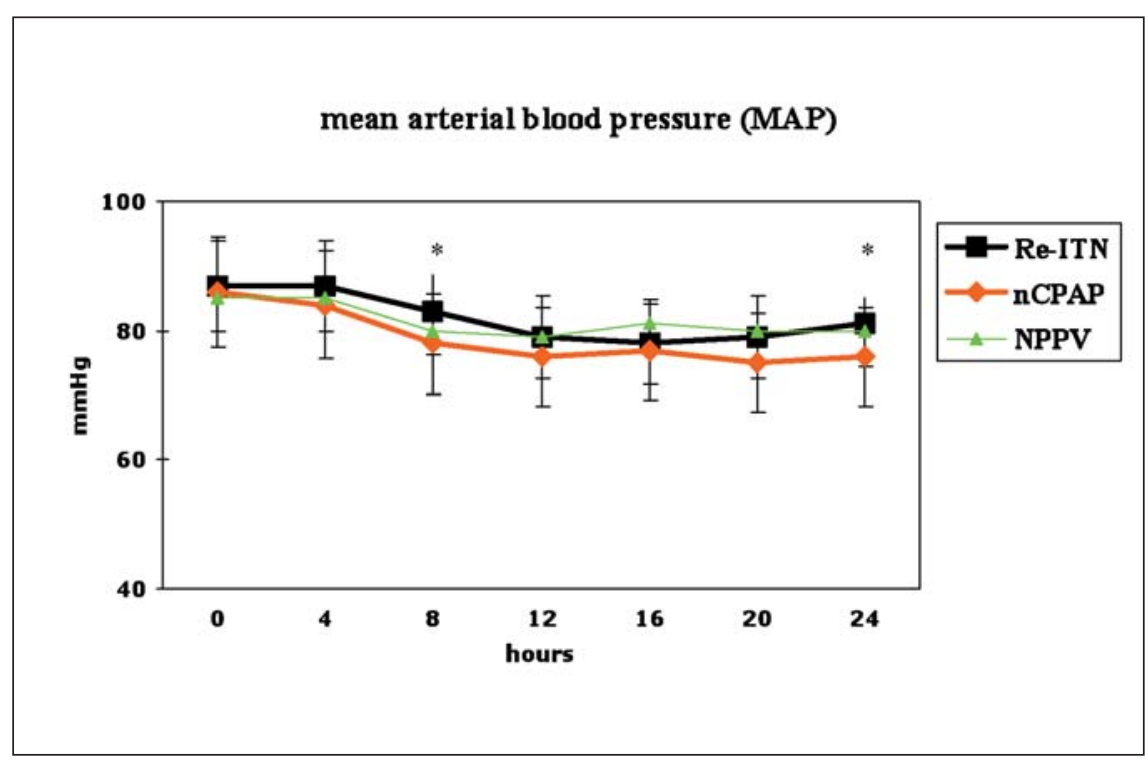

Figure 5. - Mean arterial blood pressure (MAP) during the first 24 hours of observation $(*=\mathrm{p}<0.05$ for group A [re-ITN] vs. group B [nCPAP]).

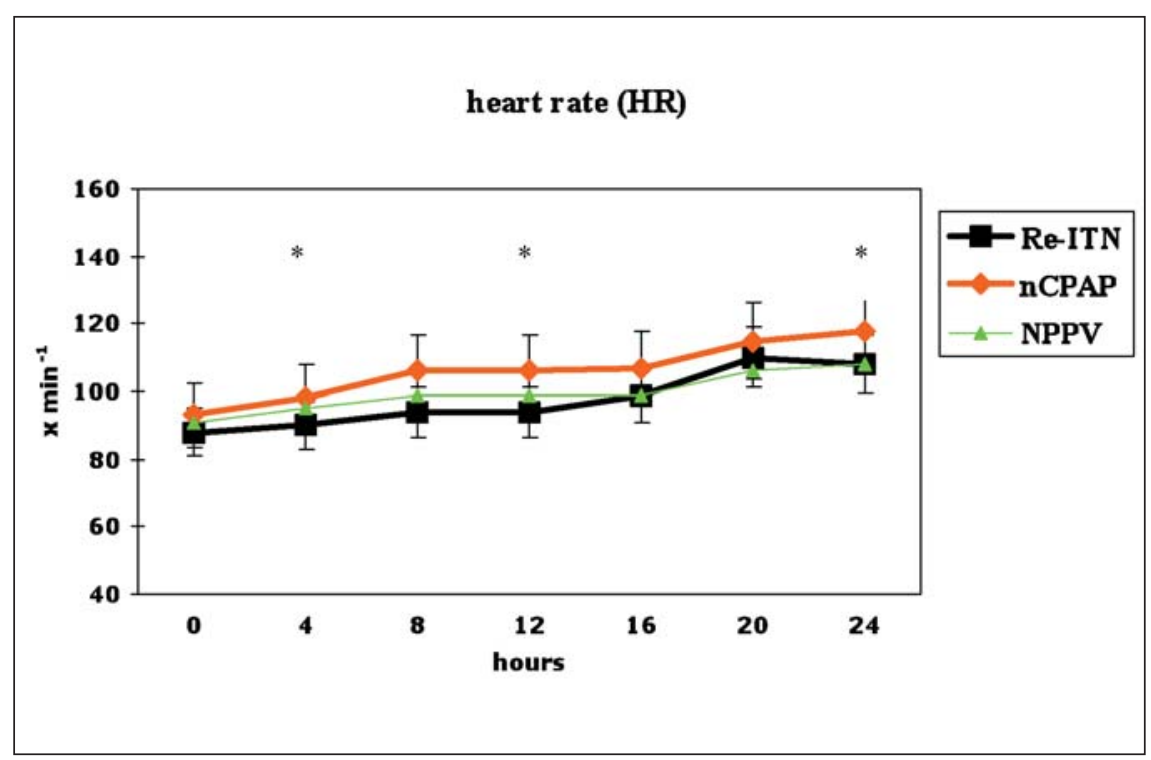

Figure 6. - Heart rate (HR) during the first 24 hours of observation $(*=\mathrm{p}<0.05$ for group A [re-ITN] vs. group B [nCPAP]). tool that enables to shorten stays at ICU with all corresponding economic advantages and may prevent from pneumonia; however, it should not be burdened with a higher rate of respiratory failure afterwards. The aim of the current study was to compare different types of invasive and non-invasive therapy in cases of respiratory failure following coronary surgery.

Nasal CPAP is a device for patients breathing spontaneously, it is easy to implement and the technical requirements are simple. It has been proven effective in acute respiratory distress due to cardiogenic pulmonary edema [6], acute exacerbation of chronic obstructive pulmonary disease (COPD) [7] and chest wall diseases including neurogenic diseases [8]. Also positive effects in atelectasis and postoperative hypoxemia have been described [9]. Considering the efficacy, it is also important to apply effective airway pressures. Studies in patients who had undergone major cardio-thoracic surgery have already shown that only airway pressures beyond $10 \mathrm{~cm} \mathrm{H}_{2} \mathrm{O}$ within the facemask were effective in keeping the intrathoracic airway pressures positive within the entire respiratory cycle, which is mandatory for improving pulmonary function and for avoiding the derecruitment of lung areas [10].

A few more studies have focused on the role of non-invasive ventilation as breathing support in general and especially in cardio-thoracic patient cohorts. In these investigations the authors were not able to prove the beneficial effects of this device, such as reduction of pulmonary infections or duration of stay at ICU or in hospital [11, 12]. Furthermore Böhner and colleagues claim even for a prophylactic use of non invasive breathing supports in early periods of oxygenation failure following primarily early extubation [13]. These findings are congruent to our current series: we found significantly shorter durations of stay at ICU and in hospital as well as a lower incidence of mortality and major complications. The 
only exception represent sternal wound complications which were significantly higher in group B. Hemodynamic changes, however, were more pronounced in patients receiving non-invasive respiratory support. It is remarkable that only $22 \%$ and $25 \%$ of group $\mathrm{C}$ and $\mathrm{B}$, respectively, were once more reintubated after a period of non invasive ventilation.

Taken together NCPAP and NPPV are technically simple, inexpensive and well tolerated methods to restore or even improve pulmonary function following coronary surgery. Thus, the prophylactic and therapeutic use is recommended in these type of surgery and should be preferred to early reintubation thus avoiding a subsequent prolonged course of mechanical ventilation. Such non-invasive tools do not, however, represent a promising therapeutic option in cases of impaired consciousness or hypercapnic state. Additionally, it is of great importance to take special care of possible sternal wound complications, especially in high risk populations $[14,15]$.

\section{Riassunto}

Background: L'incidenza di insufficienza respiratoria dopo cardiochirurgia è in aumento. Scopo del presente lavoro è valutare se la pressione continua nasale positiva nelle vie aeree (NCPAP) migliora il trasferimento di ossigeno polmonare e può evitare la reintubazione dopo cardiochirurgia, rispetto alla ventilazione non invasiva a pressione positiva (NPPV).

Metodi: Per un periodo di 2 anni sono stati analizzati tutti i pazienti intubati nelle prime 12 ore dopo cardiochirurgia, nei quali il trasporto di ossigeno $\left(\mathrm{PaO}_{2} / \mathrm{FIO}_{2}\right)$ deteriorava senza ipercapnia, cosi da rientrare nei criteri di reintubazione: gruppo $A=$ reintubazione immediata $(n=88)$, gruppo $B=N C$ $P A P(n=173)$, gruppo $C=N P P V(n=18)$.

Risultati: Dopo un periodo di NCPAP o NPPV, $25.4 \%$ dei pazienti del gruppo B e $22.2 \%$ del gruppo $C$ sono stati re-intubati. Tutti gli altri pazienti dei gruppi $B$ e $C$ sono stati svezzati da questi dispositivi $(B=34.3 \pm 5.9$ ore $; C=26.4 \pm 4.4$ ore $; p<0.05)$ $e$ risultavano ben ossigenati dalla mascherina facciale a pressione ambiente $\left(\mathrm{PaO}_{2} / \mathrm{FIO}_{2}: \mathrm{B}, 138 \pm\right.$ 13; C, $140 \pm 13$ ). Nel gruppo A abbiamo riscontrato una maggiore mortalità $(7.95 \%)$ rispetto al gruppo $B(4.04 \%)$ e $C(5.55 \%)$, rispettivamente. I pazienti sottoposti a NCPAP soffrivano più frequentemente di lenta cicatrizzazione sternale $(A=4.5 \%, B$ $=8.6 \% ; p<0.05$ ).

Conclusioni: la reitubazione dopo cardiochirurgia dovrebbe essere evitata poiché la NCPAP e la NVVP sono sicure ed efficaci nel migliorare l'ossigenazione nella maggior parte dei pazienti che presentano un insufficienza respiratoria non ipercapnica.
Parole chiave: cardiochirurgia, insufficienza respiratoria, reintubazione, ventilazione non invasiva a pressione positiva (NPPV), pressione continua nasale positiva nelle vie aeree (NCPAP).

\section{Conflict of interest statement}

All authors disclose any financial and personal relationships with other people or organizations that could inappropriately influence (bias) their work.

\section{References}

1. Mangano DT, Siliciano D, Hollenberg M, et al. Postoperative myocardial ischemia. Therapeutic trials using intensive analgesia following surgery. Anesthesiology 1992; 76: 342-353.

2. Williamson JA, Webb RK, Szekely S, Gillies ER, Dreosti AV. The Australian Incident Monitoring Study. Difficult intubation: An analysis of 2000 incident reports. Anaesth Intensive Care 1993; 21: 602-607.

3. Engoren M. Efficacy of capnometry in ventilatory management of cardiac patients. J Cardiothorac Vasc Anesth 1993; 7: 538-540.

4. Brochard L, Mancebo J, Wysocki M, et al. Noninvasive ventilation for acute exacerbations of chronic obstructive pulmonary disease. N Engl J Med 1995;333: 817-822.

5. Gross SB. Early extubation: preliminary experience in the cardiothoracic patient population. Am J Crit Care 1995; 4: 262-266

6. Meduri GU, Turner RE, Abou-Shala N, Wunderink R, Tolley E. Non-invasive positive pressure ventilation via face mask. Chest 1996; 109: 179-193.

7. Hillberg RE, Johnson DC. Non-invasive ventilation. $N$ Engl J Med 1997; 337: 1746-1752.

8. deLucas P, Tarancon C, Puente L, Rodriguez C, Tatay E, Monturiol LM. Nasal continuous positive airway pressure in patients with COPD in acute respiratory failure. Chest 1993; 104: 1694-1697.

9. Thommi G. Nasal CPAP in treatment of persistent atelectasis. Chest 1991; 99: 1551.

10. Dehaven CB, Hurst JM, Branson RD. Postextubation hypoxemia treated with a continuous positive airway pressure mask. Crit Care Med 1985; 13: 46-48.

11. Kindgen-Milles D, Müller E, Buhl R, et al. Nasal continuous positive airway pressure reduces pulmonary morbidity and length of stay following thoracoabdominal aortic surgery. Chest 2005; 128: 821-828.

12. Jousela I, Räsänen J, Verkkala K, Lamminen A, Mäkeläinen A, Nikki P. Continuous positive airway pressure by mask in patients after coronary surgery. Acta Anaesthesiol Scand 1994; 38: 311-316.

13. Bohner H, Kindgen-Milles D, Grust A, et al. Prophylactic nasal continuous positive airway pressure after major vascular surgery: results of a prospective randomized trial. Langenbecks Arch Surg 2002; 387: 21-26.

14. Jung W, Meyerfeldt U, Birkemeyer R. Atrial arrhythmias after cardiac surgery in patients with diabetes mellitus. Clin Res Cardiol 2006, Suppl. 1; 95: I88-97.

15. Fetter M. Diabetes and cerebrovascular disease. Clin Res Cardiol 2006, Suppl. 1; 95: I59-62. 